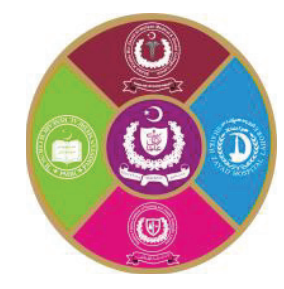

\title{
Nigella sativa can Cure Hepatotoxicity Caused by Pyrazinamide Administration; A Lead from Animal Experiment
}

${ }^{1}$ Amtul Hafeez, ${ }^{2}$ Zunera Hakim, ${ }^{3}$ Neelofar Yousaf, ${ }^{4}$ Abdul Mudabbir Rehan, ${ }^{5}$ Shahnaz Fatima, ${ }^{6}$ Rukhsana Munawwar

${ }^{1}$ Department of Pharmacology, Islam Medical College, Sialkot

${ }^{2}$ Department of Pharmacology, HITEC Institute of Medical Sciences, Taxila

${ }^{3}$ Department of Pharmacology, Akhtar Saeed Medical College, Lahore

${ }^{4}$ Department of Pharmacology, Gomal Medical College, Dera Ismail Khan

${ }^{5}$ Department of Pharmacology, Sahara Medical College, Narowal

${ }^{6}$ Department of Pharmacology, Islamic International Medical College, Rawalpindi

\begin{abstract}
Introduction: Hepatoxicity is a well known adverse effect of pyrazinamide a commonly used anti tuberculous drug, with no certified remedy. Phytochemicals could be a possible avenue for hepatoprotection. Aims \& Objectives: To study the hepatoprotective effect of Nigella sativa in low and high doses on PZA induced liver injury in mice. Place and duration of study: The study was conducted from April 2017 to June 2017 at Department of Pharmacology and Therapeutics \& multidisciplinary research lab, Islamic International Medical College, Rawalpindi. Material \& Methods: Sixty white albino mice (male) were divided into four groups randomly. Group A served as control group. Oral Pyrazinamide $500 \mathrm{mg} / \mathrm{kg} / 5 \mathrm{ml}$ glucose saline suspension was administered for 6 weeks to Group B (hepatotoxic group) alone and to Groups C and D in combination with Nigella sativa in a low dose of $500 \mathrm{mg} / \mathrm{kg}$ and high dose of $1000 \mathrm{mg} / \mathrm{kg}$ respectively. The extent of hepatotoxicity was determined by measurement of serum ALT, ALP and GGT. Results: PZA alone resulted in markedly elevated ALT, ALP and GGT $(82.8,319.1$ and $37 \mathrm{U} / \mathrm{L}$ respectively) as compared to control group i.e $(\mathrm{ALT}=27.4 \mathrm{U} / \mathrm{L}, \mathrm{ALP}=96.4 \mathrm{U} / \mathrm{L}, \mathrm{GGT}=9.3 \mathrm{U} / \mathrm{L})$. In groups $\mathrm{C}$ and $\mathrm{D}$ a non-significant increase of biochemical markers i.e, (ALT=38.4 $\pm 7.89 \mathrm{U} / \mathrm{L}$, ALP $185 \pm 39.74$, GGT24.1 $\pm 5.89 \mathrm{U} / \mathrm{L})$ and $(\mathrm{ALT}=36.7 \mathrm{U} / \mathrm{L}$, $\mathrm{ALP}=93.5 \mathrm{U} / \mathrm{L}, \mathrm{GGT}=15.8 \mathrm{U} / \mathrm{L}$ ) respectively. Conclusion: Nigella sativa has hepatoprotective effects against PZA induced liver injury in both low and high doses.
\end{abstract}

Key words: Hepatotoxicity, Nigella Sativa, Pyrazinamide.

\section{INTRODUCTION}

The "Captain of all these men of death", tuberculosis (TB) has covered a millennium era journey from being an incurable curse to a curable infection. However, even today TB stands as a challenging enemy threatening to defeat the human race by killing 1.5 million every year. ${ }^{1}$ For treating tuberculosis the standard first-line quadruple regimen consists of isoniazid, rifampicin, pyrazinamide, and ethambutol. ${ }^{2}$ The obligation of using multidrug régimes has been linked with augmented incidence of adverse reactions which may vary from mild to fatal. Antituberculosis druginduced liver injury (ATLI) is one of most common adverse effect blamable for over $7 \%$ of all toxic effects. The manifestation of ATLI during the mentioned TB treatment ranges from $2.0 \%$ to $28.0 \%{ }^{3}$ Among all first line antituberculosis (ATT) drugs, pyrazinamide (PZA) is the most common source of ATLI that causes termination of drug administration \& compromising treatment efficiency. ${ }^{4}$

PZA is a "bactericidal" ATT drug used in the initial part of TB treatment along with other drugs. The addition of PZA has condensed the duration of ATT regime from 9 to 6 months. PZA is a prodrug which is converted by pyrazinamidase to pyrazinoic acid (PA), which inhibits the nucleic acid metabolism of mycobacterial cell. Regardless of the major role of PZA, the estimated $2.6 \%$ risk of hepatic injury with PZA containing treatment cannot be overlooked. ${ }^{5}$

The severity of this hepatic injury is greater than that of isoniazid and rifampin. ${ }^{6}$ The prevalence of 
liver disease rises with increasing the dose of PZA $(30-40 \mathrm{mg} / \mathrm{kg})^{7}$

Hepatic injury due to PZA is both dose related \&idiosyncratic. Till now the toxic mechanism of PZA induced liver injury remains blurred, studies have come up with the role of reactive metabolites $\&$ free radicals in this problem. PZA is metabolized by amidase \& xanthine oxidase to pyrazinoic acid (PA) and 5 hydroxyprazinoic acid (5-OH PA) which are responsible for PZA induced hepatic damage. ${ }^{8}$ Also free radicals are generated as result of transformation of nicotinamide acetyl dehydrogenase levels. ${ }^{9}$

Since ancient eras, human being is using herbs for the cure of several medical conditions including liver ailments. Studies have revealed that app. $65 \%$ of patients with liver diseases in United States of America and Europe use herbal preparations. ${ }^{10}$ Shortage of drugs which protect the liver is a universal fact that is providing a big research gap in current decades for medicinal herbs. So many natural products have been scrutinized for their effects in hepatic disorders. Nigella sativa (NS) appeared as a marvelous therapeutic herb with numerous biological actions like anti-inflammatory, antioxidant \&anti-antiangiogenic etc. ${ }^{11}$ All these therapeutic actions can be credited to thymoquinone (TQ); the active ingredient of NS. These properties are responsible for the hepatoprotective role of $N S$ against chemical induced hepatic injury. ${ }^{12}$ Study has also proved improvement of the injurious effects of ischemic reperfusion hepatic injury by $N S .^{13}$ Reduction in indicators of oxidative stress and rise in the levels of antioxidants are the required values of management with $N S$.

\section{MATERIAL AND METHODS}

A randomized controlled study was conducted for 3 months (from April to June 2017). The approval was given by Ethical Committee. This study has been carried out at the animal house of NIH, Islamabad and Pharmacology department of Islamic International Medical College, Rawalpindi. Blood sample evaluation was done at multidisciplinary research Lab of same college.

60 mice were taken through non-probability method \& were randomly divided into 4 groups with 15 mice in each group.

Animals used: White male albino mice of 2 months age, having 25-50 grams weight were taken for study. Mice were kept under standard required conditions i.e. Humidity 40-60\%, temperature $20 \pm$ $2^{0} \mathrm{C}, \& 12 \mathrm{hr}$. light/dark cycle with water and food ad libitum. Mice were acclimatized for 1 week before any intervention.

\section{Chemicals:}

Research grade salt of PZA was obtained from Pfizer Pharmaceuticals. Nigella sativa seeds were bought and certified by National Agriculture Research Centre (NARC), Islamabad. Electrical grinder was used to convert Nigella sativa seeds into fine powder. Glucose water was then added into powder to form Suspension. 1 gram NS powder was added to $5 \mathrm{ml}$ of glucose water.

Experimental design: Following 4 groups were formed. Chow and drugs were administered through oral gavage for 6wks:

Group A: Animal in control group were given chow \& glucose water

Group B: Mice of group B received 500mg/kg PZA added in glucose water OD. ${ }^{14}$

Group C: Group C mice were given low dose Nigella sativa seeds powder $500 \mathrm{mg} / \mathrm{kg}$ dissolved in glucose water along with $500 \mathrm{mg} / \mathrm{kg}$ PZA.

Group D: This group received high dose of Nigella Sativa seeds powder $1000 \mathrm{mg} / \mathrm{kg}$ dissolved in glucose water along with $500 \mathrm{mg} / \mathrm{kg}$ of PZA. ${ }^{15}$

\section{Blood samples collection:}

Blood samples were collected at day 0 for baseline LFT's (2 mice from each group). Blood samples from 3 mice of each group was drawn after 3 weeks to find out the changes. Collection of blood samples of remaining 10 mice from all groups was done at the end of study i.e, (6 weeks). Samples were collected through cardiac puncture. A total volume of $0.8-1.5 \mathrm{ml}$ of blood was taken in sterile bottles.

\section{Markers of liver disorder}

\section{Evaluation of serum ALT, ALP \& GGT}

Blood samples were centrifuged to get serum for the estimation of ALT, ALP \& GGT by standard kits.

\section{Statistical analysis:}

Analysis of data was done by using SPSS 21. Quantitative data was given as Mean \pm S.D. Post hoc Tukey was applied for multiple comparisons among groups. $P$ value $<0.05$ was considered as significant.

\section{RESULTS}

\section{Nigella sativa effect on serum ALT}

PZA administration caused significant rise in ALT levels i-e, $(82.8 \pm 21.88 \mathrm{U} / \mathrm{L})$ in comparison

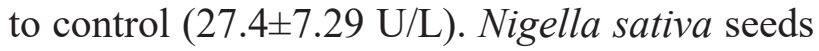
powder in both low \&high doses has prevented the rise in ALT levels after six weeks of parallel 
administration of PZA (Table-1). Post Hoc comparison confirmed significant results.

\section{Nigella sativa effect on serum ALP}

There is significant increase in ALP levels of group B mice which received PZA compared to control group A. ALP level in group C $(185 \pm 39.74 \mathrm{U} / \mathrm{L}) \&$ group D $(93.5 \pm 43.59 \mathrm{U} / \mathrm{L})$ was significantly reduced in Group $\mathrm{C}$ and Group D which were administered Nigella sativa seeds powder in low and high doses respectively (Table-1). Post Hoc comparison confirmed significant results.

\section{Nigella sativa effect on GGT}

Levels of serum GGT were markedly raised in $\mathrm{PZA}$ receiving group $\mathrm{B}$ as compared to mice in control Group A. GGT values declined in mice of Group C \&D treated with low and high doses of Nigella sativa seeds powder (Table-1). Post Hoc comparison confirmed significant results.

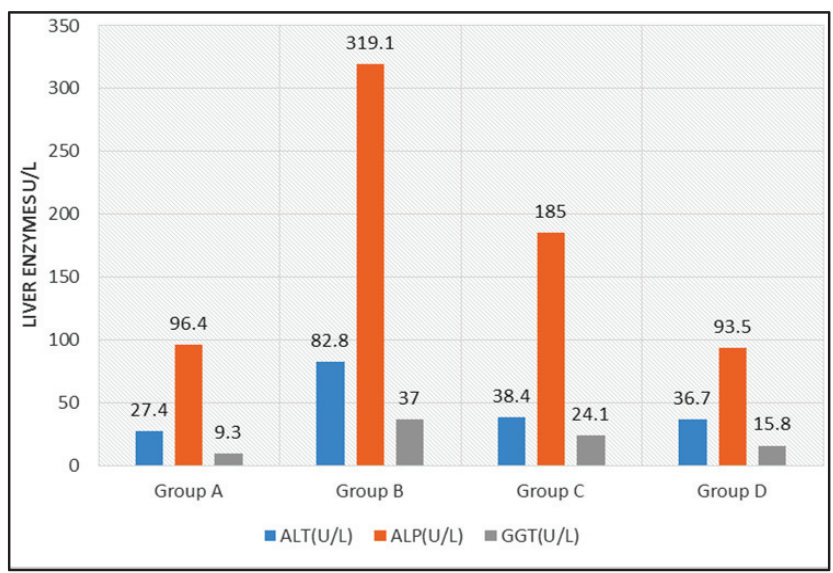

Fig-1: Mean values of ALT, ALP and GGT of all groups after six weeks of study.

\begin{tabular}{|l|l|l|l|}
\hline $\begin{array}{l}\text { Group } \\
(\mathrm{n}=15)\end{array}$ & ALT(U/L) & ALP(U/L) & GGT(U/L) \\
\hline Group A & $27.4 \pm 7.29$ & $96.4 \pm 29.58$ & $9.3 \pm 4.37$ \\
\hline Group B & $82.8 \pm 21.88^{* \mathrm{a}}$ & $319.1 \pm 109.24^{* \mathrm{a}}$ & $37 \pm 8.28^{* \mathrm{a}}$ \\
\hline Group C & $38.4 \pm 7.89^{* \mathrm{~b}}$ & $185 \pm 39.74 * \mathrm{~b}$ & $24.1 \pm 5.89^{* \mathrm{~b}}$ \\
\hline Group D & $36.7 \pm 8.17 * \mathrm{~b}$ & $93.5 \pm 43.59^{* \mathrm{~b}}$ & $15.8 \pm 4.82^{* \mathrm{~b}}$ \\
\hline
\end{tabular}

Table-1: Plasma Analysis of all Treatment Groups after six weeks

$* \mathrm{a}=\mathrm{p}<0.001$ when compared with Group A (Control)

$* \mathrm{~b}=\mathrm{p}<0.001$ when compared with Group B (PZA)

\section{DISCUSSION}

Anti-tuberculosis drugs are known to cause idiosyncratic hepatic injury globally. Burden of drug induced liver toxicity due to these drugs is not only a result of its prevalence/incidence, but also of its outcome and severity. Pakistan has 19.6\% patients suffering from hepatic injury after using ATT medicines in initial few weeks of intensive management period. ${ }^{16}$ Clinical appearances can vary from asymptomatic rise in liver enzymes to fatal fulminant hepatic failure. ${ }^{17}$ Despite its frequent use throughout the world from decades, pathogenesis of ATLI is not well understood. Possible mechanism given by researchers is that decreased glutathione (GSH) along with induction of oxidative stress due to intermediates produced by metabolism of ATT drugs is responsible for ATLI. ${ }^{18}$

PZA adversely affects liver's antioxidant protective system. Taking PZA once daily for six weeks in a dose $500 \mathrm{mg} / \mathrm{kg}$ resulted in elevation of GGT and liver transaminases i.e, ALT\& ALP. Our study results were validated by Khudur and Ahmed who proved increased ALT, AST, ALP, malionaldehyde levels and marked reduction in GSH with use of PZA. ${ }^{19}$ Raised hepatic enzymes i.e, ALT, ALP, GGT \& bilirubin and decrease in levels of antioxidant enzymes i.e, CAT, SOD, GSH peroxidase was detected by Panda \& fellow researchers in rats treated with ATT drugs. This features the important character of oxidative stress in pathology of PZA induced liver toxicity.

Present literature has declared the favorable role of antioxidants in the oxidative stress like liver damage. Studies have also mentioned the hepatoprotective role of numerous herbs against chemical induced hepatic injury due to their antioxidant outcomes. Present research assessed the practicality of Nigella sativa as liver savior in PZA induced liver insult in mice. Concurrent use of low \& high dose Nigella sativa with PZA preserved hepatocellular integrity as manifested by lowered levels of hepatic enzymes. Nigella sativa has markedly reduced ALT, ALP \& GGT levels in comparison to group treated with PZA. Compatible with our conclusions is the study lead by Jadhav et al. who examined the effects of NS oil in hepatic injury caused by antituberculous drugs given to albino rats. ${ }^{20}$ They verified that administration of $N S$ oil along with antituberculous drugs reduced ALT, ALP, AST, bilirubin and total protein levels markedly. Our research is also backing the previously stated findings that $N S$ restored the levels of enzymes in hepatic disease caused by carbon tetrachloride, paracetamol $1^{15,21} \&$ tertbutyl hydroperoxide. ${ }^{22}$

Though the exact mechanism of hepatoprotection of Nigella sativa is not known, its beneficial role can be credited to its ability to decrease oxidative stress which is the dominant mechanism of hepatotoxicity 
caused by PZA. Although the manifold chemical composition of Nigella sativa makes it exigent to assign its hepatoprotective role to one of its component, yet thymoquinone (TQ) has taken the credit with its confirmed hepatoprotective and antioxidant effect.

Consequently, the current study established the concept that Nigella sativa seeds when taken orally have protective role in liver damage in albino mice due to PZA.

\section{CONCLUSION}

Nigella sativa has great potential hepatoprotective herb against PZA related hepatic insult and in the lack of a proven hepatoprotective medication, Nigella sativa can act as an alternative agent for preventing ATLI.

\section{REFERENCES}

1. Gülbay BE, Gürkan ÖU, Yildiz ÖA, Önen ZP, Erkekol FÖ, Baccioglu A, et al. Side effects due to primary antituberculosis drugs during the initial phase of therapy in 1149 hospitalized patients for tuberculosis. Respiratory medicine. 2006; 100(10):1834-42.

2. Jeong I, Park J-S, Cho Y-J, Yoon HI, Song J, Lee C-T, et al. Drug-induced hepatotoxicity of anti-tuberculosis drugs and their serum levels. Journal of Korean medical science. 2015; 30(2): 167-72.

3. Shang P, Xia Y, Liu F, Wang X, Yuan Y, Hu D, et al. Incidence, clinical features and impact on anti-tuberculosis treatment of anti-tuberculosis drug induced liver injury (ATLI) in China. PLoS One. 2011; 6(7):e21836.

4. Saha A, Shanthi FX M, Winston A B, Das S, Kumar A, Michael JS, et al. Prevalence of Hepatotoxicity From Antituberculosis Therapy: A Five-Year Experience From South India. Journal of primary care \& community health. 2016; 7(3):171-4.

5. Chang KC, Leung CC, Yew WW, Lau TY, Tam CM. Hepatotoxicity of pyrazinamide: cohort and case-control analyses. American journal of respiratory and critical care medicine. 2008; 177(12):1391-6.

6. Yee D, Valiquette C, Pelletier M, Parisien I, Rocher I, Menzies D. Incidence of serious side effects from first-line antituberculosis drugs among patients treated for active tuberculosis. American journal of respiratory and critical care medicine. 2003; 167(11):1472-7.
7. Tostmann A, Boeree MJ, Aarnoutse RE, De Lange W, Van Der Ven AJ, Dekhuijzen R. Antituberculosis drug-induced hepatotoxicity: concise up-to-date review. Journal of gastroenterology and hepatology. 2008; 23(2): 192-202.

8. Shih T-Y, Pai C-Y, Yang P, Chang W-L, Wang N-C, Hu OY-P. A novel mechanism underlies the hepatotoxicity of pyrazinamide. Antimicrobial agents and chemotherapy. 2013; 57(4):1685-90.

9. Saukkonen JJ, Cohn DL, Jasmer RM, Schenker S, Jereb JA, Nolan CM, et al. An official ATS statement: hepatotoxicity of antituberculosis therapy. American journal of respiratory and critical care medicine. 2006; 174(8):935-52.

10. Stickel F, Schuppan D. Herbal medicine in the treatment of liver diseases. Digestive and liver disease. 2007; 39(4):293-304.

11. Asadi-Samani M, Kafash-Farkhad N, Azimi N, Fasihi A, Alinia-Ahandani E, Rafieian-Kopaei M. Medicinal plants with hepatoprotective activity in Iranian folk medicine. Asian Pacific Journal of Tropical Biomedicine. 2015; 5(2): 146-57.

12. Khader M, Eckl PM. Thymoquinone: an emerging natural drug with a wide range of medical applications. Iranian journal of basic medical sciences. 2014; 17(12):950.

13. Yildiz F, Coban S, Terzi A, Ates M, Aksoy N, Cakir $\mathrm{H}$, et al. Nigella sativa relieves the deleterious effects of ischemia reperfusion injury on liver. World journal of gastroenterology: WJG. 2008; 14(33):5204.

14. Kovalenko V, Bagnyukova T, Sergienko O, Bondarenko L, Shayakhmetova G, Matvienko A, et al. Epigenetic changes in the rat livers induced by pyrazinamide treatment. Toxicology and applied pharmacology. 2007; 225(3):293-9.

15. Hassan AS, Ahmed JH, Al-Haroon SS. A study of the effect of Nigella sativa (Black seeds) in isoniazid (INH)-induced hepatotoxicity in rabbits. Indian journal of pharmacology. 2012; 44(6):678.

16. Rahman N, Ali S, Khan MY, Umar M, Iqbal Z, Basit A, et al. Frequency of Risk Factors for Hepatotoxicity in Patients with Antituberculosis Drug Induced Hepatitis. Pakistan Journal of Chest Medicine. 2015; 21(1):04-9.

17. Ramappa V, Aithal GP. Hepatotoxicity related to anti-tuberculosis drugs: mechanisms and management. Journal of clinical and experimental hepatology. 2013; 3(1):37-49. 
18. Chowdhufw A, Santha A, Kundu S, ItIlUkhefljee A. Induction of oxidative stress in antitubercular drug-induced hepatotoxicity.

19. S Hassan A, Ahmed J, Al-Haroon S. A study of the effect of Nigella sativa (Black seeds) in isoniazid (INH)-induced hepatotoxicity in rabbits. 2012; 678-82 p.

20. Jadhav R, Mateenuddin M. Effect of Nigella Sativa Oil on Hepatotoxicity Induced by Antitubercular Drugs in Albino Rats. 2013.

21. Rodbard H, Jellinger P, Davidson J, Einhorn D, Garber A, Grunberger G, et al. Statement by an American Association of Clinical Endocrinologists/American College of Endocrinology consensus panel on type 2 diabetes mellitus: an algorithm for glycemic control. Endocrine practice. 2009; 15(6):540-59.

22. Mollazadeh H, Hosseinzadeh $H$. The protective effect of Nigella Sativa against liver injury: a review. Iranian journal of basic medical sciences. 2014; 17(12):958.

\section{The Authors:}

Dr. Amtul Hafeez

Assistant Professor

Pharmacology,

Islam Medical College, Sialkot
Dr. Zunera Hakim

Assistant Professor

Pharmacology,

HITEC Institute of Medical Sciences, Taxila

Dr. Neelofar yousaf

Assistant Professor

Pharmacology,

Akhtar Saeed Medical College, Lahore

Dr. Abdul Mudabbir Rehan

Assistant Professor

Pharmacology,

Gomal Medical College, Dera Ismail Khan

Dr. Shahnaz Fatima

Associate Professor

Pharmacology,

Sahara Medical College, Narowal

Dr. Rukhsana Munawwar

Assistant Professor

Pharmacology,

Islamic International Medical College, Rawalpindi

\section{Corresponding Author:}

Dr. Amtul Hafeez

Assistant Professor

Pharmacology,

Islam Medical College, Sialkot

E-mail: haajaramatullaah1@gmail.com 